\title{
Antiplatelet therapy for transient ischaemic attacks and acute minor strokes: current best practice and future
}

\author{
Chamila Mettananda ${ }^{1}$ \\ ${ }^{1}$ University of Kelaniya Faculty of Medicine
}

November 13, 2020

\begin{abstract}
In patients presenting with transient ischaemic attack and acute minor noncardioembolic ischemic stroke (NIHSS score [?]3) who did not receive IV alteplase, treatment with dual antiplatelet therapy with aspirin and clopidogrel, started within 24 hours after symptom onset and continued for 21 days is effective in reducing recurrent ischemic stroke up to 90 days from symptom onset. However, as the long-term risk of major disabling bleeding with aspirin-based antiplatelet treatment is higher in patients aged 75 years or older, routine co-prescription of proton pump inhibitor should be encouraged.
\end{abstract}

\section{Title page}

Title: Antiplatelet therapy for transient ischaemic attacks and acute minor strokes: current best practice and future

Running title: Antiplatelet therapy for minor strokes

Authors' name and affiliation:

Kukulege Chamila Dinushi Mettananda, PhD, Department of Pharmacology, Faculty of Medicine, University of Kelaniya, Sri Lanka, Chamila@kln.ac.lk, Chamilametta@hotmail.com, 0094714816310

\section{Name of Corresponding Author}

Dr Chamila Mettananda,

Department of Pharmacology,

Faculty of Medicine,

University of Kelaniya

Ragama (10110)

Sri Lanka,

chamila@kln.ac.lk, chamilametta@hotmail.com

Tel: 0094714816310 , fax 0094112958337.

\section{Acknowledgments}

none

Funding - none 


\section{Conflict of Interest Statement}

No conflict of Interest .

\section{Abstract \\ Title: Antiplatelet therapy for transient ischaemic attacks and acute minor strokes: current best practice and future}

\section{Running title: Antiplatelet therapy for minor strokes}

In patients presenting with transient ischaemic attack and acute minor noncardioembolic ischemic stroke (NIHSS score [?]3) who did not receive IV alteplase, treatment with dual antiplatelet therapy with aspirin and clopidogrel, started within 24 hours after symptom onset and continued for 21 days is effective in reducing recurrent ischemic stroke up to 90 days from symptom onset. However, as the long-term risk of major disabling bleeding with aspirin-based antiplatelet treatment is higher in patients aged 75 years or older, routine co-prescription of proton pump inhibitor should be encouraged.

Key words : antiplatelet, stroke, Transient-ischaemic-attack, prevention, dual-antiplatelet

\section{Take-home messages}

- In patients presenting with transient ischaemic attack and acute minor noncardioembolic ischemic stroke should receive dual antiplatelet therapy with aspirin and clopidogrel for 21 days

- Aspirin should be started within 24 hours after symptom onset

- Routine Co-prescription of proton pump inhibitors with aspirin-based antiplatelet treatment is encouraged in patients aged 75 years or older in order reduce major bleeding complications

\section{Manuscript}

A significant percentage (15-26\%) of strokes are preceded by transient ischemic attacks (TIA) or minor strokes (1). Recurrent strokes following TIA or minor stroke is highest in the first 48 hours through the first week (2-6). Early assessment and initiation of preventive treatment at emergency TIA clinics have shown to reduce the early recurrence of stroke at 90-days by about $80 \%$ in EXPRESS (Effect of urgent treatment of transient ischemic attack and minor stroke on the early recurrent stroke) and SOS-TIA studies $(7,8)$. Therefore, starting secondary prophylaxis measures as soon as possible is very important.

Aspirin is the most effective treatment and the only antiplatelet treatment that has evidence to have reduced recurrent disabling ischemic strokes in patients with noncardioembolic ischemic stroke during the first 90 days (9-12). Time-course analysis of acute stroke trials had observed, $60-70 \%$ reduction in risk and severity of early recurrent stroke with early initiation of aspirin following TIA and ischaemic stroke (13). Furthermore, the benefit of aspirin is highest within the first 6 weeks and it gradually wains off by 12 weeks and the benefits become less clear beyond 90 days (13). The benefit of aspirin is more when initiated following mild to moderate strokes than major stroke (13). Therefore, early initiation of aspirin, preferably within 24-48 hours had been the guideline for long $(14,15)$. However, it is also important to note that

the long-term risk of major bleeding is higher and more sustained in patients receiving aspirin-based antiplatelet treatment long term without routine proton pump inhibitor use, and half of the major bleeds were in patients aged 75 years or older (16).

Dual antiplatelet therapy with aspirin and clopidogrel combination in acute ischaemic strokes or TIA was studied in two major trials. CHANCE (Clopidogrel with aspirin in acute minor stroke or transient ischemic attack) trial studied aspirin vs aspirin and clopidogrel combination administered within 24 and continued for 21 days following TIA or minor stroke and demonstrated that aspirin and clopidogrel combination was more effective in reducing recurrent strokes at 90 days without a significant increase in bleeding risk (17). But, POINT (Platelet-Oriented Inhibition in New TIA and Minor Ischemic Stroke) Trial observed that early initiation of aspirin and clopidogrel combination vs aspirin, given for 90 days caused $25 \%$ increased risk reduction of recurrent stroke but at the expense of $0.5 \%$ increased risk of bleeding (18). However, a 
pooled analysis confirmed that the benefit of this dual antiplatelet therapy is confined to the first 21 days after minor ischemic stroke or high-risk TIA (19). Therefore, it is now recommended in guidelines to treat TIA and minor strokes with dual antiplatelet therapy (aspirin and clopidogrel) started within 24 hours after symptom onset and to continue for 21 days in patients presenting with minor ischemic stroke (NIHSS score [?]3) of noncardioembolic origin who did not receive IV alteplase (14).

However, clopidogrel is ineffective in patients who are carriers of CYP2C19 loss-of-function alleles, which is reported to be present in 15-60\% of Asians depending on the ethnic group(20). Clopidogrel is a pro-drug needing activation in the liver whereas the newer P2Y12 receptor blocker; ticagrelor has a direct action and does not need activation in the liver $(21,22)$. Ticagrelor is a quick-acting, predictable (as not dependent on CYP2C19 gene polymorphism) and reversible platelet inhibitor unlike clopidogrel with an antidote also being developed in phase II trials(23). Therefore, ticagrelor is being studied in clinical trials for secondary prevention of TIA and strokes.

SOCRATES (Acute Stroke Or Transient IsChaemic Attack TReated With Aspirin or Ticagrelor and Patient OutcomES) trial studied aspirin vs ticagrelor started within 24 hours of the index event. Ticagrelor was not found to be superior to aspirin in reducing recurrent cardiovascular events (myocardial infarctions(MI), strokes and death) at 90 days (24) and therefore, ticagrelor is not recommended over aspirin in the early management of acute ischaemic strokes in current AHA/ASA guidelines(14). Even though ticagrelor in SOCRATES trial did not show benefit in achieving the primary outcome of reducing recurrent MI, stroke or death, a stratified analysis, showed benefit in the reduction of all stroke(24). Later in subgroup analyses of SOCRATES trial observed that ticagrelor was substantially more efficacious In large artery disease(25) and in patients with a background history of aspirin use (26).

Dual antiplatelet therapy with aspirin and ticagrelor was compared with aspirin and clopidogrel in a small, unblinded Chinese study; PRINCE (Platelet Reactivity in Acute Non-disabling Cerebrovascular Events) trial and observed that aspirin and ticagrelor combination is superior in reducing platelet reactivity at 90 days(27). THALES (The Acute STroke or Transient IscHaemic Attack Treated With TicAgreLor and ASA for PrEvention of Stroke and Death) trial was studied aspirin vs aspirin and ticagrelor combination treatment of 30 days in mild to moderate (NIHSS $<5$ ) stroke patients, over 40 years of age started within 24 hours. The results were that the aspirin and ticagrelor combination was superior to aspirin in reducing stroke or death $(1.1 \%)$ but at the expense of increased rate of severe bleeding $(0.4 \%)(24)$.

Currently, as of emerging strategies, CHANCE-II trial is in progress comparing dual antiplatelet therapy with aspirin and clopidogrel vs aspirin and ticagrelor given for 21 days following acute TIA/stroke and will hopefully bring new recommendations in future (ClinicalTrials.gov no: NCT04078737).

Therefore, in conclusion, treatment with dual antiplatelet therapy (aspirin and clopidogrel) started within 24 hours after symptom onset and continued for 21 days is recommended in patients presenting with TIA or minor noncardioembolic ischemic stroke (NIHSS score [?]3) who did not receive IV alteplase, as the current best practice of secondary prevention.

\section{References}

1. Rothwell PM, Coull AJ, Giles MF, Howard SC, Silver LE, Bull LM, et al. Change in stroke incidence, mortality, case-fatality, severity, and risk factors in Oxfordshire, UK from 1981 to 2004 (Oxford Vascular Study). Lancet (London, England). 2004;363(9425):1925-33.

2. Chandratheva A, Mehta Z, Geraghty OC, Marquardt L, Rothwell PM. Population-based study of risk and predictors of stroke in the first few hours after a TIA. Neurology. 2009;72(22):1941-7.

3. Johnston SC, Gress DR, Browner WS, Sidney S. Short-term prognosis after emergency department diagnosis of TIA. Jama. 2000;284(22):2901-6.

4. Rothwell PMW, C. P. Timing of TIAs preceding stroke: time window for prevention is very short. Neurology. 2005;64(5):817-20. 
5. Lovett JK, Dennis MS, Sandercock PAG, Bamford J, Warlow CP, Rothwell PM. Very Early Risk of Stroke After a First Transient Ischemic Attack. Stroke. 2003;34(8):e138-e40.

6. Amarenco PL, Philippa C. Labreuche, ulienAlbers, Gregory W. Bornstein, Natan M. Canhão, Patrícia Caplan, ouis R. Donnan, Geoffrey A., Ferro JM, Hennerici MG, Molina C, Rothwell PM, Sissani L, et al. One-Year Risk of Stroke after Transient Ischemic Attack or Minor Stroke. New England Journal of Medicine. 2016;374(16):1533-42.

7. Lavallee PC, Meseguer E, Abboud H, Cabrejo L, Olivot JM, Simon O, et al. A transient ischaemic attack clinic with round-the-clock access (SOS-TIA): feasibility and effects. The Lancet Neurology. 2007;6(11):95360 .

8. al RPMe. Effect of urgent treatment of transient ischaemic attack and minor stroke on early recurrent stroke (EXPRESS study): a prospective population-based sequential comparison. The Lancet. 2005;370(9596):1432-42.

9. The International Stroke Trial (IST): a randomised trial of aspirin, subcutaneous heparin, both, or neither among 19435 patients with acute ischaemic stroke. International Stroke Trial Collaborative Group. Lancet (London, England). 1997;349(9065):1569-81.

10. CAST: randomised placebo-controlled trial of early aspirin use in 20,000 patients with acute ischaemic stroke. CAST (Chinese Acute Stroke Trial) Collaborative Group. Lancet (London, England). 1997;349(9066):1641-9.

11. Hackam DG, Spence JD. Antiplatelet Therapy in Ischemic Stroke and Transient Ischemic Attack. Stroke. 2019;50(3):773-8.

12. Baigent C, Blackwell L, Collins R, Emberson J, Godwin J, Peto R, et al. Aspirin in the primary and secondary prevention of vascular disease: collaborative meta-analysis of individual participant data from randomised trials. Lancet (London, England). 2009;373(9678):1849-60.

13. Rothwell PM, Algra A, Chen Z, Diener HC, Norrving B, Mehta Z. Effects of aspirin on risk and severity of early recurrent stroke after transient ischaemic attack and ischaemic stroke: time-course analysis of randomised trials. Lancet (London, England). 2016;388(10042):365-75.

14. Powers WJ, Rabinstein AA, Ackerson T, Adeoye OM, Bambakidis NC, Becker K, et al. Guidelines for the Early Management of Patients With Acute Ischemic Stroke: 2019 Update to the 2018 Guidelines for the Early Management of Acute Ischemic Stroke: A Guideline for Healthcare Professionals From the American Heart Association/American Stroke Association. Stroke. 2019;50(12):e344-e418.

15. Stroke and transient ischaemic attack in over 16s: diagnosis and initial management. NICE guideline: National Institute for Health and Clinical Excellence 2019 [updated May 2019.

16. Li L, Geraghty OC, Mehta Z, Rothwell PM. Age-specific risks, severity, time course, and outcome of bleeding on long-term antiplatelet treatment after vascular events: a population-based cohort study. Lancet (London, England). 2017;390(10093):490-9.

17. Wang Y, Wang Y, Zhao X, Liu L, Wang D, Wang C, et al. Clopidogrel with Aspirin in Acute Minor Stroke or Transient Ischemic Attack. New England Journal of Medicine. 2013;369(1):11-9.

18. Johnston SC, Easton JD, Farrant M, Barsan W, Conwit RA, Elm JJ, et al. Clopidogrel and Aspirin in Acute Ischemic Stroke and High-Risk TIA. New England Journal of Medicine. 2018;379(3):215-25.

19. Pan Y, Elm JJ, Li H, Easton JD, Wang Y, Farrant M, et al. Outcomes Associated With ClopidogrelAspirin Use in Minor Stroke or Transient Ischemic Attack: A Pooled Analysis of Clopidogrel in High-Risk Patients With Acute Non-Disabling Cerebrovascular Events (CHANCE) and Platelet-Oriented Inhibition in New TIA and Minor Ischemic Stroke (POINT) Trials. JAMA Neurol. 2019;76(12):1466-73. 
20. Wang Y, Zhao X, Lin J, Li H, Johnston SC, Lin Y, et al. Association Between CYP2C19 Loss-of-Function Allele Status and Efficacy of Clopidogrel for Risk Reduction Among Patients With Minor Stroke or Transient Ischemic Attack. Jama. 2016;316(1):70-8.

21. Hulot JS, Bura A, Villard E, Azizi M, Remones V, Goyenvalle C, et al. Cytochrome P450 2C19 lossof-function polymorphism is a major determinant of clopidogrel responsiveness in healthy subjects. Blood. 2006;108(7):2244-7.

22. Mega JL, Close SL, Wiviott SD, Shen L, Hockett RD, Brandt JT, et al. Cytochrome p-450 polymorphisms and response to clopidogrel. The New England journal of medicine. 2009;360(4):354-62.

23. Bergmark BA. Real\&\#x2010;World Comparison of Ticagrelor and Clopidogrel: Rosetta Stone or Lost in Translation? Journal of the American Heart Association. 2020;9(14):e017888.

24. Johnston SC, Amarenco P, Denison H, Evans SR, Himmelmann A, James S, et al. Ticagrelor and Aspirin or Aspirin Alone in Acute Ischemic Stroke or TIA. New England Journal of Medicine. 2020;383(3):207-17.

25. Amarenco P, Albers GW, Denison H, Easton JD, Evans SR, Held P, et al. Efficacy and safety of ticagrelor versus aspirin in acute stroke or transient ischaemic attack of atherosclerotic origin: a subgroup analysis of SOCRATES, a randomised, double-blind, controlled trial. The Lancet Neurology. 2017;16(4):301-10.

26. Wong KSL, Amarenco P, Albers GW, Denison H, Easton JD, Evans SR, et al. Efficacy and Safety of Ticagrelor in Relation to Aspirin Use Within the Week Before Randomization in the SOCRATES Trial. Stroke. 2018;49(7):1678-85.

27. Wang Y, Chen W, Lin Y, Meng X, Chen G, Wang Z, et al. Ticagrelor plus aspirin versus clopidogrel plus aspirin for platelet reactivity in patients with minor stroke or transient ischaemic attack: open label, blinded endpoint, randomised controlled phase II trial. BMJ (Clinical research ed). 2019;365:12211-l. 